\title{
Elemental analysis of individual nanograins in meteorites by ICP- TOF-MS
}

\author{
M. NAKAZATO ${ }^{1}$, S. YAMASHITA ${ }^{1}$, AND T. HiRATA ${ }^{1 *}$ \\ ${ }^{1}$ University of Tokyo, 7-3-1 Hongo, Tokyo 113-0033, Japan \\ (*correspondence: hrt1@eqchem.s.u-tokyo.ac.jp)
}

\section{Introduction}

The matrix in chondrites is a mixture of nanometer- to micrometer-sized grains each of which records the formation processes in the early Solar system [1]. The elemental and isotopic analyses of the individual grains have been retarded mainly due to difficulties in both the analysis and handling. Recently, rapid and sensitive analytical technique for nanoscale substances using ICP-MS was described [2]. To derive the elemental data from individual grains in chondrites, we have developed a new analytical technique for submicronsized grains with ICP-MS. To test the reliability of data obtained here, elemental ratios of major elements were measured on about 400 grains in the matrix of chondrite, collected by the laser ablation in liquid (LAL) technique [3].

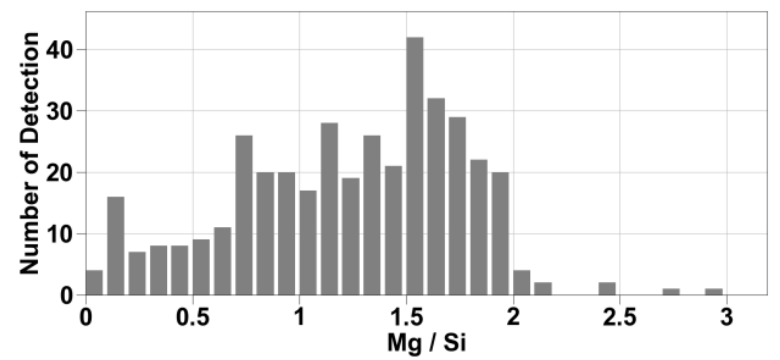

Figure 1: Elemental ratio of $\mathrm{Mg}$ and $\mathrm{Si}$ in each detected silicate grain in Allende meteorite.

\section{Discussion of Results}

The sample grains were introduced into the ICP through a solution nebulization technique. In this study, we focused on the elemental ratio analysis from $\mathrm{Mg}$-Si bearing minerals. The resulting $\mathrm{Mg} / \mathrm{Si}$ ratios for most of the grains were below 2, and the $\mathrm{Mg} / \mathrm{Si}$ ratios of around 1.5 were frequently observed (Fig. 1). This result seemed to reflect elemental compositions of major minerals, possibly olivine and orthopyroxene [4], that formed nanograins. Further experiments may derive whole elemental data for each grain more accurately and precisely.

[1] Scott \& Krot (2005) ASP Conference Series 341, 15-53.

[2] Laborda et al. (2014) Anal. Chem. 86, 2270-2278.

[3] Okabayashi et al. (2011) JAAS 26, 1393-1400.

[4] Rubin (1997) Meteoritics \& Planetary Science 32, 231-247. 